\title{
Pengembangan Kurikulum PTAI \\ Menghadapi Masyarakat Ekonomi ASEAN (MEA)
}

\author{
Marlina $^{1 *}$, Iswati $^{2 *}$ \\ ${ }^{1}$ STKIP Nurul Huda OKU Timur \\ ${ }^{2}$ Universitas Muhammadiyah Metro \\ *Marlina@stkipnurulhuda.ac.id \\ ** Iswatiummetro@yahoo.com
}

\begin{abstract}
Abstrak
Pendidikan sangat sentral peranannya dalam menanggulangi akses negatif dari perkembangan zaman. Pendidikan adalah bidang yang bersentuhan langsung dengan kebutuhan hidup manusia agar tetap eksis dan dapat bertahan (survive) dan kurikulum adalah salah satu aspek penting dalam pendidikan yang mempunyai peran signifkan menentukan kemajuan peradaban serta menjawab tantangan kehidupan. Maka berdasarkan hal tersebut tidak mengherankan pembahasan mengenai kurikulum hampir selalu ada dalam setiap pengkajian masalah-masalah pendidikan. Karena disadari benar bahwa kurikulum merupakan salah satu alat yang sangat strategis dan menentukan dalam pencapaian tujuan pendidikan. Walaupun Negara-negara di kawasan ASEAN sangat majemuk ditinjau dari aspek agama yang dianutnya akan tetapi kerjasama perlu dilakukan untuk membina harmoni di kawasan tersebut. Di tengah perkembangan zaman yang pesat membuat Perguruan Tinggi Agama Islam harus dapat memenuhi tuntunan zaman sesuai dengan visi dan misi sebagai lembaga tinggi yang bermartabat. Dalam rangka menghadapi Masyarakat Ekonomi ASEAN (MEA) PTAI perlu melakukan upaya maksimal untuk merekonstruksi kurikulum yang ada sebagai salah satu lembaga pendidikan Islam. yang berkualitas dengan inovasi model-model pengembangan kurikulum yang relevan dengan isu-isu globalisasi.
\end{abstract}

Kata kunci: Metode Kurikulum PTAI, Masyarakat Ekonomi ASEAN.

\section{PENDAHULUAN}

Kurikulum sebagai rancangan pendidikan mempunyai kedudukan yang sangat strategis dalam seluruh aspek kegiatan pendidikan. Pendidikan pada hakikatnya adalah usaha membudayakan manusia atau memanusiakan manusia. Mengingat pentingnya peranan kurikulum di dalam pendidikan dan perkembangan kehidupan peserta didik, maka dalam penyusunan kurikulum tidak bisa dilakukan tanpa menggunakan landasan yang kokoh dan kuat.

Pelaksanaan Pendidikan Agama Islam secara yuridis mendapatkan jaminan yang kuat yaitu Undang-undang Nomor 20 Tahun 2003 Tentang Sistem Pendidikan Nasional pasal 15 ayat 1 yang menjelaskan "Jenis pendidikan mencakup pendidikan umum, kejuruan, akademik, profesi, vokasi, keagamaan, dan khusus". Selain ketentuan tersebut, pada pasal 37 ayat (1 dan 2) ditegaskan bahwa isi kurikulum setiap jenis jalur dan jenjang pendidikan wajib memuat pendidikan agama, pendidikan kewarganegaraan, bahasa, matematika, ilmu pengetahuan alam, ilmu pengetahuan sosial, seni budaya, pendidikan jasmani dan olahraga, keterampilan dan kejuruan serta muatan lokal.(Marlina Marlina; Sayid Amrullah, 2017, p. 36)

Kurikulum di Perguruan Tinggi Agama Islam harus berbeda dengan Kurikulum Pendidikan Dasar. Dalam lingkup pendidikan dasar harus lebih menekankan pada pembentukan karakter peserta didik, penanaman nilai-nilai agama, budaya dan karakter bangsa harus ditanamkan pada masa-masa 
awal perkembangan kejiwaan peserta didik agar memiliki fondasi yang kuat dalam menghadapi masa-masa rawan timbulnya dekadensi moral dan kenakalan remaja serta dalam rangka bersosialisasi dengan lingkungannya yang lebih luas.

Kurikulum PTAI menekankan kepada kompetensi peserta didik yang mengacu kepada kompetensi yang harus dimiliki oleh seorang guru dan dosen sebagaimana tercantum dalam undangundang No.14 tahun 2005 tentang Guru dan Dosen yaitu kompetensi pedagogik, kompetensi kepribadian, kompetensi sosial, dan kompetensi profesional. (E.Mulyasa,H.4). Menurut keputusan Menteri Agama Nomor 353Tahun 2014 tentang Pedoman Penyusunan Kurikulum PTAI pasal 9, bahwa Kompetensi lulusan dikelompokkan menjadi empat kompetensi, yaitu kompetansi dasar, kompetansi utama, kompetensi pendukung dan kompetensi lainnya. (Muhaimin,2014,h.233) Mengingat lulusan PTAI (khususnya LPTK/Lembaga Pendidikan Tenaga Kependidikan) adalah calon-calon guru/pendidik.

Perkembangan zaman yang sangat pesat membuat Perguruan tinggi agama Islam harus dapat memenuhi tuntunan zaman sesuai dengan visi dan misi sebagai lembaga tinggi yang bermartabat. Visi PTAI, misalnya "Menjadikan PTAI yang membangun manusia yang memiliki kekokohan akidah dan kedalaman spiritual, keagungan aklaq, keluasan ilmu, dan kematangan professional", sementara misi PTAI, misalnya:

1. Menyelenggarakan pendidikan dan pengajaran, penelitian, dan pengabdian kepada masyarakat dalam bidang ilmu pengetahuan, teknologi dan seni yang islami.

2. Mengembangakan dan menyebarluaskan ilmu pengetahuan, teknologi dan seni yang Islami.

3. Memberikan ketauladanan dalam kehidupan atas dasar nilai-nilai Islam dan budaya Indonesia. (Muhaimin,2014,h.233-234)

Perkembangan teknologi dan peradapan yang pesat membuat tingginya keinginan manusia yang berbangsa-bangsa untuk saling kenal-mengenal dan bekerjasama, hal ini sebagaimana firman Allah Qs. Al Hujurat:13

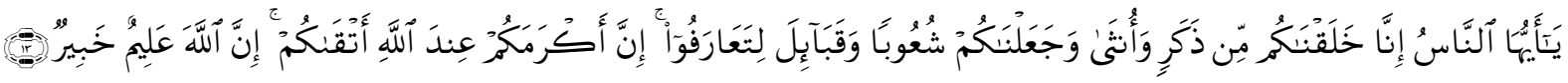

"Hai manusia! Sungguh, Kami telah menciptakan kamu dari seorang laki-laki dan seorang perempuan, kemudian Kami jadikan kamu berbangsa-bangsa dan bersuku-suku agar kamu saling kenal mengenal. Sunggu yang paling mulia di antara kamu di sisi Allah ialah orang yang paling bertakwa di antara kamu. Sungguh Allah Maha Mengetahui, lagi Maha Mengenal". (Departemen Agama RI,2004,h.517).

Maka berdasarkan firman Allah SWT., di atas Indonesia dan negara-negara Asia Tenggara lainnya, saat ini telah menjadi bagian dari pasar bebas negara-negara di Asia Tenggara yang tergabung dalam Masyarakat Ekonomi ASEAN (MEA). Menurut Abdul Rachman Husein, keinginan Allah SWT dalam menciptakan makhluk-Nya selain untuk saling mengenal satu sama lain adalah untuk dapat saling menolong juga. Inilah yang kemudian menjadi setting tujuan MEA, yang tidak 


\section{Pengembangan Kurikulum PTAI 3 Menghadapi Masyarakat Ekonomi ASEAN (MEA)}

hanya untuk membentuk perdagangan bebas (free market), melainkan juga memperkuat ekonomi negara dalam satu kawasan. Abdul Rachman Husein, 2009,h. 139).

Dalam rangka menghadapi MEA PTAI harus mengembangkan kurikulum yang ada sebagai sebagai salah satu lembaga pendidikan Islam yang menghasilkan lulusan yang memiliki kompetensi yang unggul dibidang ilmu agama dan memiliki peran yang penting dalam pertumbuhan dibidang pendidikan.

MEA sendiri bukan sekadar kompetisi tapi juga kolaborasi. Dalam hal ini peranan pendidikan Islam harus mengedepankan one vision, one identity, and one community, sehingga hasilnya akan memperkuat kolaborasi dalam bidang pendidikan Islam bukan mempertajam kompetisi yang kurang produktif. Dengan demikian, peluang yang dapat dilakukan oleh negara anggota ASEAN adalah membangun pendidikan Islam yang maju dan berdaya saing serta berperadaban maju. Adapun, aliansi strategi pendidikan Islam ASEAN adalah membangun identitas ASEAN, menciptakan rasa memiliki, mengembangkan model pendidikan Islam yang bermutu, membangun pusat unggulan studi Islam, kerangka kualifikasi dan kompetensi ASEAN, dan mutual recognation.

\section{A. PROBLEM KURIKULUM PTAI MENGHADAPI MEA}

ASEAN Economic Community (AEC) atau bisa dikenal dengan istilah Masyarakat Ekonomi Asia (MEA), pada awalnya lahir dari organisasi ASEAN yang berdiri pada tahun 1967 di Bangkok, Thailand. Organisasi ini memiliki fokus terhadap isu keamanan dan perdamaian di Asia tenggara selain isu di bidang ekonomi. Pada awal berdiri, ASEAN (Association of South East Asian Nations/Perhimpunan Bangsa-Bangsa Asia Tenggara) hanya terdiri dari lima negara pendiri, yakni Indonesia, Malaysia, Singapura, Filipina dan Thailand. Negara-negara yang berhaluan komunis di kawasan itu saat itu belum bergabung misalnya Myanmar, Laos, Kamboja san Vietnam. Dalam perkembagan selanjutnya setelah merdeka Brunai Darussalam ikut bergabung dengan ASEAN tahun 1984, dan beberapa Negara lainnya menyusul bergabung misalnya Laos dan Myanmar bergabung tahun 1997, dan Kamboja menjadi Negara ke-10 bergabung pada tahun 1998. Masyarakat Ekonomi ASEAN (MEA) merupakan realisasi pasar bebas Asia Tenggara untuk meningkatkan stabilitas perekonomian masyarakat di kawasan ASEAN, hal ini adalah bagian dari visi organisasi ASEAN di tahun 2020 mengenai ekonomi ASEAN, yaitu:

We will create a stable, prosperous and highly competitive ASEAN economic region in which there is a free flow of goods, service and investments, a freer flow of capital, equitable economic development and reduced poverty and socio-economic disparities. (ASEAN Vision, 2020, 1997).(Suteja, 2017, pp. 91-92)

Lahirnya MEA jelaslah akan berdampak pada lembaga Islam terutama PTAI sehingga pengembangan kurikulum PTAI mau tidak mau harus dilakukan inovasi kurikulum. Ada beberapa Kelemahan kurikulum PTAI, yaitu:

1. kurang relevan dengan kebutuhan masyarakat: banyak program studi yang tidak diminati masyrakat tetap dipertahankan;

2. kurang efektif, yakni tidak menjamin dihasilkannya lulusan yang sesuai dengan harapan; 
3. kurang efisien,yakni banyaknya mata kuliah dan sks tidak menjamin dihasilkannya lulusan yang sesuai harapan;

4. kurang fleksibel, yakni PTAI kurang berani secara kreatif dan bertanggung jawab mengubah kurikulum guna menyesuaikan dengan kebutuhan masyarakat (setempat, nasional atau global);

5. readibility rendah tidak komunikatif (bisa menimbulkan banyak tafsir);

6. hanya berubah deretan mata kuliah;

7. berbasis (berfokus) pada mata kuliah/penyampaian materi, bukan pada tujuan kurikuler/hasil belajar/mutu lulusan;dan

8. hubungan fungsional antarmata kuliah yang mengacu pada tujuan kurikuler kurang jelas. (Muhaimin, 2012,h.221)

Kelemahan-kelemahan kurikulum PTAI tersebut akan berdampak pada outcome lulusan yang seharusnya memiliki kompetensi unggul di masyarakat dan dunia kerja, dan lulusan PTAI akan sulit untuk bersaing di Masyarakat Ekonomi ASEAN. Hal ini tentunya akan menjadi problem yang harus diperbaiki dalam mempersiapkan lulusan PTAl yang dapat merambah dunia pasar bebas yang memiliki kompetensi dan mengedepankan nilai-nilai keislaman.

Menurut Tisna Nugraha ada tiga persoalan yang dihadapi lulusan lembaga pendidikan islam dalam menghadapi MEA diantaranya:(Lestari \& Kunci, 2014, pp. 1-2)

1. Kesiapan sumber daya manusia untuk siap pakai di dunia kerja Dalam hal ini lembaga pendidikan Islam dipandang masih belum mampu secara merata memproduksi tenaga kerja yang memiliki keterampilan dan daya saing tinggi. Dampak dari kekurangan ini adalah, posisi-posisi pekerjaan entry-level dan middle-level masih di dominasi oleh pekerja asing maupun tamatan lembaga pendidikan umum. Selain itu, lemahnya kemampuan ini, ternyata dibarengi dengan kekurangan terhdap penguasaan skill manajerial dan wawasan (leadership skills dan global exposure). Padahal kemamapuan tersebut sangat dibutuhkan bagi perusahaan ataupun dunia kerja untuk dapat unggul dalam persaingan. Tanpa kemampuan manajerial yang baik, maka pengelolaan dan tujuan organisasi tidak dapat tercapai dengan baik pula.

2. Kecakapan bahasa lulusan lembaga pendidikan Islam yang belum tergali secara maksimal. Hal ini ditandai dengan masih kurangnya dominasi keberadaan lulusan lembaga pendidikan Islam yang berperan aktif dalam dunia kerja internasional khususnya di ASEAN, serta masih rendahnya lulusan lembaga pendidikan Islam yang mampu secara aktif mempraktikan kemampuan berbahasanya. Padahal penguasaan jaringan (networking), penguasaan inovasi dan penguasaan teknologi perlu dibarengi dengan kecakapan di bidang bahasa sehingga memungkinkan terbukanya transfer knowlodge dan relasi hubungan kerja yang menguntungkan.

3. Perpindahan arus teknologi dan budaya secara global. Adanya aliran bebas perpindahan teknologi dan budaya menyebabkan kearifan lokal yang dimiliki oleh generasi muda khususnya para pemuda Islam dapat tergerus arus globalisasi yang berasal dari negara-negara anggota ASEAN. Perubahan ini akan berdampak pada krisis identitas budaya bangsa yang pada akhirnya melahirkan budaya baru serta menghilangkan budaya lama. 


\section{Pengembangan Kurikulum PTAI 5 Menghadapi Masyarakat Ekonomi ASEAN (MEA)}

Berdasarkan problem lulusan lembaga Pendidikan Islam tersebut perlunya dilakukan upaya yang maksimal untuk meramu kurikulum yang berkualitas dan inovasi model-model pengembangan kurikulum yang relevan dengan isu-isu globalisasi.

\section{B. KURIKULUM PTAI DALAM MENGHADAPI MEA}

Beberapa hal yang melatar- belakangi penyusunan kurikulum antara lain:

1. Adanya peraturan penundang undangan yang baru telah membawa implikasi terhadap paradigma pengembangan kurikulum pendidikan dasar dan menengah antara lain pembaharuan dan divensifikasi kurikulum, serta pembagian kewenangan pengembangan kurikulum.

2. Perkembangan dan perubahan global dalam berbagai aspek kehidupan yang datang begitu cepat telah menjadi tantangan nasional dan menuntut perhatian segera dan serius.

3. Kondisi masa sekarang dan kecenderungan di masa yang akan datang perlu dipersiapkan generasi muda termasuk peserta didik yang memiliki kompetensi yang multidimensional.

4. Pengembangan kurikulum harus dapat mengantisipasi persoalan-persoalan yang mempunyai kemungkinan besar sudah dan/atau akan terjadi.(Hanafi, 2014, p. 292)

Berdasarkan Landasan Sosio Histori atau dilihat dari dimensi sejarah, tujuan utama pengembangan Perguruan Tinggi Islam yaitu:

1. Untuk melaksanakan pengkajian dan pengembangan ilmu-ilmu agama Islam pada tingkat yang lebih tinggi secara lebih sistematis dan terarah;

2. Untuk melaksanakan pengembangan dan peningkatan dakwah islam;

3. Untuk melakukan reproduksi dan kaderisasi ulama dan fungsionaris keagamaan, baik pada kalangan birokrasi Negara maupun sektor swasta, serta lembaga-lembaga social, dakwah, pendidikan, dan sebagainya.

Pengembangan kurikulum di PTAl setidaknya haruslah memperhatikan empat komponen, yaitu materi, tujuan, metode dan evaluasi. Empat komponen tersebut menurut A. Rifqi amin di dalamnya harus memuat nilai-nilai ajaran islam pada setiap komponennya dan harus terjalin secara integral. (A. Rifqi Amin, 2014, h.17). Menurut pengamatan para ahli, bahwa dalam bidang social capital bangsa Indonesia ini hampir mencapai titik zero trust society, atau masyarakat yang sulit dipercaya. Masyarakat juga menghadapi globalisasi di bidang budaya, etika dan moral sebagai dampak kemajuan teknologi di bidang komunikasi dan informasi sehingga mengakibatkan perubahan budaya, etika dan moral. (Muhaimin, 2012, h.220)

PTAI sebagai Perguruan tinggi Islam perlu mengantisipasi fenomena tersebut degan cara menawarkan model-model pendidikan yang mampu mencegah fenomena tersebut. Mengembangkan kemampuan ganda diera globalisasi melalui; (Muhaimin, 2012, h.244)

Marlina $^{1}$ dan Iswati ${ }^{2}$ 
1. Etos kerja, yang menyangkut kemampuan belajar serta berfikir secara kreatif dan kritis, dan mengoptimalkan kegunaan kemampuan-kemampuan biologis dan psikologis;

2. Melek teknologi, menyangkut kemampuan berfikir, bertindak dan memanaj secara teknologis, serta memaksimalkan pemanfaatan tipe teknologi yang bermacam-macam;

3. Melek ilmu ekonomi, menyangkut kemampuan yang berfikir, bertindak dan memanaj secara ekonomis, serta mengoptimalkan penggunaan berbagai sumber yang bervariasi;

4. Melek ilmu social, menyangkut kemampuan berfikir, bertindak dan memanaj secara social dan secara social dan secara efektif mengembangakan hubungan interpersonal yang harmonis;

5. Melek ilmu politik, menyangkut kemampuan berfikir, bertindak dan memanaj secara politis dan meningkatkan win-win outcomes (hasil yang sama-sama menang);

6. Melek budaya, menyangkut kemampuan berfikir, bertindak dan memanaj secara cultural, mengoptimalkan penggunaan berbagai asset multicultural, serta mengkreasi nilai-nilai baru.

Berdasarkan Keenam kemampuan di atas dalam pengembangan kurikulum PTAl perlu dikontekstualisasikan kedalam rangkaian individualisasi, lokalisasi dan globalisasi.

\section{MODEL PENGEMBANGAN KURIKULUM PTAI BERBASIS KOMPETENSI}

Kelemahan kurikulum PTAI, yaitu (1) kurang relevan dengan kebutuhan masyarakat: banyak program studi yang tidak diminati masyarakat tetap dipertahankan; (2) kurang efektif, yakni tidak menjamin dihasilkannya lulusan yang sesuai dengan harapan; (3) kurang efisien,yakni banyaknya mata kuliah dan sks tidak menjamin dihasilkannya lulusan yang sesuai harapan; (4) kurang fleksibel, yakni PTAl kurang berani secara kreatif dan bertanggung jawab mengubah kurikulum guna menyesuaikan dengan kebutuhan masyarakat (setempat, nasional atau global); (5) readibility rendah tidak komunikatif (bisa menimbulkan banyak tafsir); (6) hanya berubah deretan mata kuliah; (7) berbasis (berfokus) pada mata kuliah/penyampaian materi, bukan pada tujuan kurikuler/hasil belajar/mutu lulusan;dan (8) hubungan fungsional antarmata kuliah yang mengacu pada tujuan kurikuler kurang jelas. (Muhaimin. 2012,h.221)

Untuk mengatasi berbagai kelemahan tersebut, maka Direktur Pertais mengambil kebijakan tentang pengembangan kurikulum, yaitu:

1. Kurikulum berbasis hasil belajar

2. Kurikulum terdiri dari kurikulum inti dan kurikulum institusional

3. Kurikulum inti $40 \%$ ditetapkan oleh pemerintah dan berlaku secara nasional sedangkan kurikulum institusional (60\%) ditetapkan oleh PTAI dan berlaku hanya di PTAI tersebut.

4. Kurikulum secara keseluruhan (inti dan institusional) ditetapkan oleh PTAI

5. Kualitas kurikulum menjadi tanggung jawab PTAI.(Nugraha, 2016, pp. 14-15) 


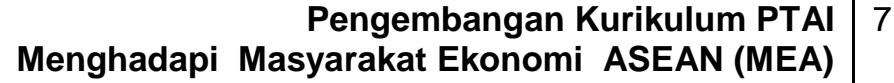

Kebijakan tersebut mengandung makna bahwa:

1. Kurikulum perlu dikembangkan dengan lebih menitik beratkan pada pencapaian target kompetensi dari pada penguasaan materi.

2. Lebih mengakomodasikan keragaman kebutuhan dan sumber daya pendidikan yang tersedia.

3. Memberikan kebebasan yang lebih luas kepada pelaksana pendidikan di PTAl untuk mengembangkan dan melaksanakan program pendi-dikan sesuai dengan kebutuhan.

4. Menggunakan prinsip kesatuan dalam kebijakan dan keragaman da-lam pelaksanaan.

5. Pengembangan kurikulum memuat sekelompok mata kuliah pengem-bangan kepribadian (MPB) pada semua program studi, serta the four fillars of education: learning to know (how and why/MKK), learning to do (MKB), learning tobe or capable to be (MPB), learning to live together (MBB). (Muhaimin. 2012,h.222)

Pengembangan kurikulum berbasis kompetensi ini diharapkan agar:

1. Mutu pendidikan lebih terjamin;

2. Lebih dapat memenuhi kebutuhan lapangan kerja; dan

3. Peran PTAl sebagai agen perubahan masyarakat dapat lebih meme-nuhi. (Muhaimin. 2012,h.222)

Pengembangan kurikulum PTAI lebih disebabkan karena kebutuhan internal dan tantangan eksternal yang berubah sangat dinamis. PTAl tidak bisa menjadi menara gading yang lepas dari dunia luar". PTAI adalah bagian dari institusi sosial (social institutions) yang saling mempengaruhi satu sama lain. Perubahan pada satu institusi, misalnya perkembangan politik atau ekonomi mengakibatkan perubahan pada institusi pendidikan. PTAI juga merupakan bagian komunitas dunia yang terus bergerak. Globalisasi berikut dampak iringannya (nurturant effect) sedikit banyak menggoyang" pertahanan PTAI. Pada aras inilah perombakan kurikulum menemukan titik terangnya.

\section{PENGEMBANGAN KURIKULUM PTAI BERBASIS KOMPETENSI KKNI}

Pengembangan kurikulum di PT dimulai dari penetapan learning outcomeyaitu pembelajaran yang diawali dari penentuan profil lulusan. Profil lulusan adalah gambaran suatu peran yang dapat dilakukan oleh lulusan, setelah dia berkiprah di masyarakat atau setelah mereka lulus di perguruan tinggi.Perubahan kurikulum tidak hanya terjadi pada tataran kebijakan dan dokumen saja, namun harus diikuti dengan perubahan implementasinya. Satu prinsip utama yang berubah dalam proses pembelajaran berbasis kompetensi di perguruan tinggi adalah bahwa, capaian hasil pembelajarannya tidak lagi bertumpu pada penguasaan isi kajian dan ilmu pengetahuan an sih, namun harus sampai bagaimana ilmu tersebut diaplikasikan dan dikembangkan di dalam peran lulusan mahasiswa setelah mereka keluar dari perguruan tinggi. Kurikulum pendidikan tinggi khususnya perguruan tinggi islam, selain bertujuan mengembangkan ilmu pengetahuan juga berprinsip terhadap perkembangan kehidupan sosial islami artinya tuntutan yang dikehendaki oleh masyarakat adalah pengabdian pada

Marlina $^{1}$ dan Iswati ${ }^{2}$ 
masyarakat baik dalam aspek sosial maupun agama. (Al-Jumbulati, Ali dan M. Arifin, 1994,h.174)

Upaya yang lazim dilakukan dalam menyusun kurikulum, terutama kurikulum yang berbasis kompetensi dalah dengan melakukan analisis SWOT (Strength, Weakness, Opportunity, Threat) dan Tracer Study serta Labor Market Signals. Kemudian setelah itu hasil kedua analisis tersebut digunakan untuk menentukan tujuan pendidikan. Tujuan pendidikan inilah yang kemudian segera dijabarkan dalam mata kuliah yang tersusun dalam tiap semester. Kemudian langkah selanjutnya adalah menjabarkan setiap mata kuliah ke dalam bahan ajar (silabus).

Alternatif penyusunan kurikulum berbasis kompetensi dimulai dari langkah:(Nugraha, 2016, pp. 14-15)

a. Penyusunan profil lulusan, yaitu peran dan fungsi yang dapat dijalankan oleh lulusan di pasar kerja,

b. penetapan kompetensi lulusan berdasarkan profil lulusan yang telah ada,

c. penentuan bahan kajian yang akan digunakan untuk mencapai kompetensi yang telah ditetapkan,

d. penetapan kedalaman dan keluasan kajian (sks) yang dilakukan dengan menganalisis hubungan dari kompetensi dan kajian yang diperlukan,

e. pendistribusian kajian tersebut ke dalam mata kuliah,

f. penyusunan struktur kurikulum dengan cara mendistribusikan mata kuliah tersebut dalam semester, pengembangan Rancangan Pembelajaran termasuk proses asesmen dan penilaiannya

g. pengimplementasian ke dalam metode pembelajaran yang ada di kelas.

\section{PENUTUP}

Kurikulum PTAl sebagai lembaga Pendidikan Islam tertinggi menghadapi berbagai tantangan menghadapi Masyarakat Ekonomi Asia (MEA), sehingganya para pemangku kebijakan perlu melakukan upaya perbaikan yang relevan dengan tututan globalisasi untuk meningkatkan mutu lulusan yang memiliki kompetansi yang unggul dan siap pakai di dunia kerja. Proses pengembangan kurikulum dapat dilakukan dengan cara memodifikasi kurikulum yang ada menjadi kurikulum yang sesuai dengan zamannya atau mengubah kurikulum yang langsung disesuaikan dengan kebutuhan zaman. Hal ini perlu diupayakan agar visi da n misi PTAI dapat terealisasi. Lulusan PTAI diharapkan memiliki mutu lulusan yang berdayasaing ditingkat lokal, regional bahkan internasional.

\section{UCAPAN TERIMAKASIH}

Peneliti mengucapkan terima kasih kepada LPPM STKIP Nurul Huda Sukaraja OKU Timur dan Tim Jurnal Al I'tibar Program Studi PAI STKIP Nurul Huda. 


\section{DAFTAR PUSTAKA}

A. Rifqi Amin,(2014). Sistem Pembelajaran pendidikan Agama Islam Pada Perguruan Tinggi Umum,(Yogyakarta: Deepublish).

Abdul Rachman Husein,(2009). Motivations of Islamic Business (Jakarta: PT elex Media Komputindo).

Al-Jumbulati, Ali dan M. Arifin. (1994). Perbandingan Pendidikan Islam (Terj). Jakarta: Rineka Cipta.

Departemen Agama RI,(2004). Al Qur'an dan Terjemahan AL Jumanatul Ali, (Bandung:CV Penerbit J-ART).

E.Mulyasa, Standar Kompetensi Sertifikasi Guru, (Bandung:PT Remaja Rosdakarya).

Muhaimin, Pengembangan Kurikulum PAl disekolah, madrasah dan Perguruan Tinggi (Jakarta: PT RajaGrasindo Persada, 2014).

Hanafi, M. (2014). Pengembangan kurikulum perguruan tinggi agama islam. Islamuna, 1(2), 255-296.

Lestari, K. E. K. A., \& Kunci, K. (2014). Issn 2338-2996, 2(November), 36-46.

Marlina Marlina; Sayid Amrullah. (2017). Perbandingan Efektivitas Social Interaction Models Dan Personal Family Models Dalam Meningkatkan Hasil Belajar Pendidikan Agama Islam. Al I'tibar: Jurnal Pendidikan Islam, 4(1), 35-49.

Nugraha, M. T. (2016). Pengembangab Model Kurikulum Pendidikan Agama Islam (PAI) Menuju Ekonomi Asean (MEA). At-Turats, 10(1), 21. Retrieved from file://C:/Users/USER/Downloads/447-1522-1-PB.pdf

Suteja, J. (2017). Model-model pembelajaran dalam kurikulum berbasis kompetensi KKNI di perguruan tinggi. Jurnal Edueksos, VI(1), 81-100.

Sukardi. 2006. Metode Penelitian untuk Pendidikan. Jakarta: Raja Grafindo Persada. 